\title{
Main Trends in Development of Media and Internet Resources in the Independent Kyrgyzstan
}

\section{Aida Duishonbaeva1, Aida Apysheva1, Gulzhamal Bekmyrzaeva1, Tazhibai Aitbaev1, Elmira Salieva2 ${ }^{2}$, Zhypargul Abdullaeva ${ }^{3 *}$ (1)}

\author{
${ }^{1}$ Department of General History and Teaching Methods, Osh State University, Osh, Kyrgyzstan \\ ${ }^{2}$ Department of Kyrgyzstan History, Archeology and Ethnology, Osh State University, Osh, Kyrgyzstan \\ ${ }^{3}$ Science and Research Department, Osh State University, Osh, Kyrgyzstan \\ Email: *jypar.science@oshsu.kg
}

How to cite this paper: Duishonbaeva, A., Apysheva, A., Bekmyrzaeva, G., Aitbaev, T., Salieva, E., \& Abdullaeva, Z. (2021). Main Trends in Development of Media and Internet Resources in the Independent Kyrgyzstan. Advances in Journalism and Communication, 9, 74-83.

https://doi.org/10.4236/ajc.2021.92006

Received: April 23, 2021

Accepted: May 28, 2021

Published: May 31, 2021

Copyright $\odot 2021$ by author(s) and Scientific Research Publishing Inc. This work is licensed under the Creative Commons Attribution International License (CC BY 4.0).

http://creativecommons.org/licenses/by/4.0/

\begin{abstract}
The article is providing analysis of the main trends in the development of media in independent Kyrgyzstan, and the spread of Internet resources. Many countries have the right to choose their own media model for development. It is a historical fact that independent Kyrgyzstan has chosen the freedom of speech and press during the years of independence. On the mass media front in the sovereign country, new non-traditional, format, range, themes, and views of media, which were not previously immersed in the communist party ideology, began to appear. In a short time, most of them were able to find their place among the people and readers. Media in Kyrgyzstan has changed its direction in politics, society, and economics.
\end{abstract}

\section{Keywords}

Kyrgyzstan, Political Process, Mass Media, Front Media, Non-Traditional Editions, Internet Resources, Democracy, Right, Modernization, Function, Internet-Media, Multimedia, Interactivity

\section{Introduction}

Currently, the country's media is looking for ways to create new professional information organizations (USAID, 2021), because media level does not meet modern requirements. The first media development association was formed in the course of this search, additionally, the development of mass media resources includes the following activities (Semakula et al., 2019) shown in Figure 1. The 


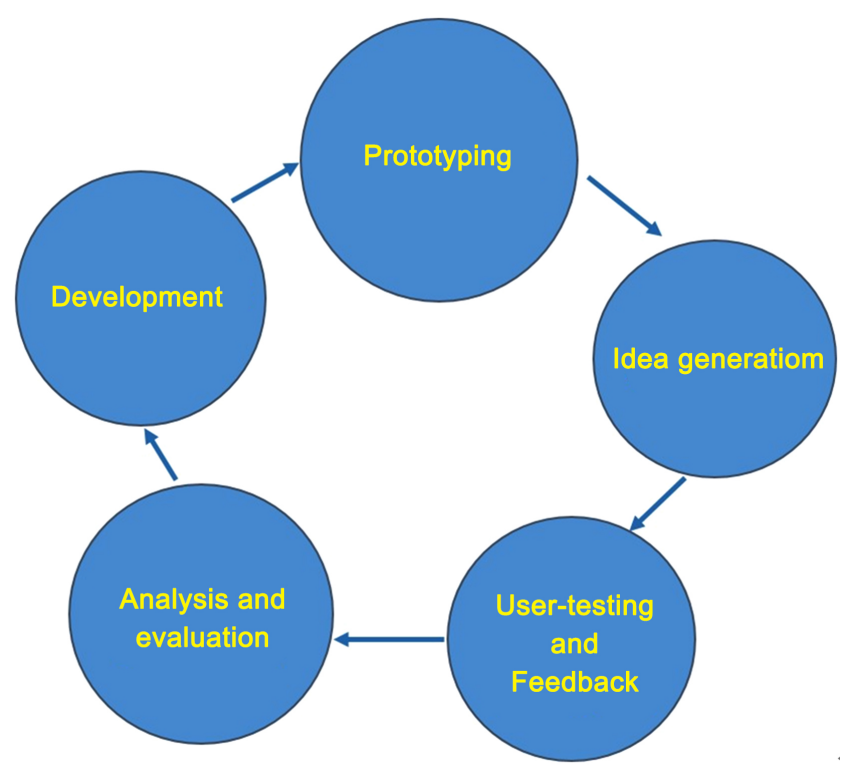

Figure 1. Activities in the development of mass media resources.

great novelty of the media in Kyrgyzstan needs constant search and tireless work of the media front. Public authorities control activities of the media in the Kyrgyz Republic following the Mass Media Law (CIS Legislation, 2021).

The role and place of media in the political arena in the independent Kyrgyz Republic have great importance. Over the past $15-20$ years, the emergence of the Internet in the independent Kyrgyzstan media space with its widespread use in a short period by all population segments had an emphasis on rapid access to information, which led to the widespread distribution of non-traditional media including blogs, posts, etc. (Panusheva, 2010). Traditional media refers to its most common components, which are almost constantly used: radio, television, press, outdoor advertising, while non-traditional media are types of advertising that include Internet, computer games, and mobile phones (Tsakhaev \& Musieva, 2008). Online media containing news, blogs, wikis, and other new media platforms providing users with the opportunity to share news, express their opinion, comments, exclusive photos, and videos (Shagdarova \& Vilmova, 2018), while social media includes the citizens' voices on a wide range of topics on Twitter, Facebook, WhatsApp, YouTube, Facebook Messenger, WeChat, QQ, and Instagram (Pulido et al., 2018).

In this article, the main trends in the development of media in independent Kyrgyzstan and sustainable distribution of Internet resources are learned and analyzed.

\section{Research Methods and Materials}

Literature analysis based on the published works and the emergence of Internet resources with their broad impact on political, economic, social, cultural aspects in society and population psychological life were analyzed. This study period is 2000-2015 years in Kyrgyzstan. Research methods are based on inclusive re- 
search, which includes mass media (newspapers, magazines, journals). Today's mass media source waves include popular wide range content public copyright and re-writing information field and comprehensive internet sources.

Main trends in the development of media, emergence, and distribution of Internet resources explored. Research materials in this work are Internet media including web with online media, performing functions in current conditions, as well as traditional media forms such as newspapers, magazines, television, radio broadcasting, and information production that created with a certain frequency by the journalist team.

\section{Mass Media}

Mass media play an important role in the life of modern society (Alvarez-Mon et al., 2018). The media, being official and unofficial, perform various functions: informational (Lund \& Wang, 2021), analytical, entertaining (Ahmed \& Cho, 2019) and advertising (Saima \& Khan, 2021). Media is one of the key tools of the country's political system; acquisition of sovereignty and independence in Kyrgyzstan allowed growth and development in the country and society routine. If in the Soviet government years there were counted the number of mass media, then during the years of independence in the Kyrgyz Republic, 450 newspapers and magazines were opened and functioned, where more than three thousand journalists worked.

\section{Internet}

Internet is a modern field of realization of the functions of all social institutions. The level of penetration of the Internet is an indicator of economic development, civic activism and political freedom of society (Lukina \& Fomicheva, 2005). 10 years ago, these indicators were the level of quality and freedom of the media. The emergence of the Internet facilitated by the development of information and telecommunication technologies, the introduction of the Internet in the general educational space. In addition, an important factor in the development of the Internet was the crisis of print media, associated with difficult economic conditions. Internet media functions provide following sources:

1) Exclusive materials content;

2) Inner and outer reference materials;

3) Application contents including photographs, video materials, comments;

4) Multimedia, cartoons, games;

5) Advertisement blogs.

What does the Internet represent as a means of mass information? Internetmass media (also web-means of mass information, online-means of mass information), a kind of resources on the Internet, performing the functions of mass media, in modern conditions. Internet media such as YouTube, Twitter, blogs or Facebook (Charron \& Annoni, 2021), as well as traditional media newspapers, magazines, television, radio broadcasting, produce information, created by a 
certain periodicity of the journalistic team and reflecting society life. The functions of media on the Internet are related to the classical functions of traditional mass media, but specific to the strength of the technical capabilities of the Internet. Functions of Internet media:

1) Preserve all the media content;

2) Acquire a specific, conditioned environment.

In this network, a special meaning acquires a communicative function. In contrast to traditional media, the Internet resource is more successful than a two-way model of communication. An Internet reader is not only a recipient of information but also a full participant in information exchange.

Communication is real time in the same communicative environment. Communication is defined as a process of coding and transforming information from the source to the recipient; mass communication is related to a process of spreading information using technical means from a single center to a numerically large audience (Fedorova, 2009; Fomicheva, 2012). For example, additional communicative website functions allow arranging topics discussions, participating in surveys and popular topics rating. One can participate in online press conferences and ask questions to an expert or journalist. However, for the realization of this potential, it is necessary to apply the same force as the journalist's side, as well as the audit side, that is, with their side the necessary activity and access to the Internet. Internet information can fulfill the value-regulating function of the media as a whole. For this purpose, they are located with unique capabilities, conditioned by efficiency and interactivity. Therefore, these functions can be performed by Internet edition also the functions of the forum, the channel of social participation and recreation:

1) The forum function is possible only in bilateral communication. Thus, new opportunities opened for a multifaceted discussion of the problem, public discourse between the population and the authorities. However, not all mass media implement this function;

2) The functions of a multifaceted discussion, it is impossible without the readiness of journalists to organize and stimulate it, and readers to use such opportunity;

3) The recreational function is for specific feature locations that create interactivity and hypertextuality.

Investigative Internet resources are the same as traditional media, but only on the Internet. Together with that, there is a multitude of information resources in the World Communication Network, which also perform these functions and correspond to the signs. All sites have content, text and audio-video files that are updated with a specified periodicity. There is also a state of people who fill and model these resources. The author, site editor, technical editor and designer belong to him. Considering this, it is difficult to identify the fundamental differences between the information resource and the Internet.

Resource as the media undergoes registration in special issues regulating their 
activity, and legally defined as a media, endowed with rights and obligations, provided by law. G. Lassuella most clearly defines the difference between the Internet and the Internet resource (Tikhomirova, 2017). The communicator is a specialist who holds a certain position in the professional hierarchy of the editorial office in the Internet field. He has the rights and obligations provided for journalist's editorial and legislations of professional activities, which imposed on legal, professional and ethical responsibility.

Within the framework of their professional rights as an Internet journalist, that is, a communicator can be accredited, as well as he can send a corresponding request and receive information from the authorities, which an employee of an Internet resource cannot do. The message that sends to its audience on the Internet carries a mass character and public significance. The site of any organization contains content, an interesting narrow audience. For example, the site of the Interstate Fund for Humanitarian Affairs has specific content that is of interest to not every user. For the content of the Internet-as in the traditional media, the universality of the theme, documentary and social significance. On the Internet, the channel is characterized by periodic updates. The Internet, in contrast to the site, the resource is updated more often and without a fixed periodicity, which depends on the current parameters of the event. The periodicity of updating the content of the Internet resource does not carry a regular character. The Internet audience, in contrast to its large resource distributed throughout the social stratum, differentiated by gender, age and social relevance.

Internet resources clearly represent the age, gender, interests and financial capabilities of their audience. Content corresponding to their interests is not attractive to the mass reader, and the universality of the topic, documentation and scale of the Internet content is attractive to all users. The effects produced by the Internet have already been listed above. In this regard, it is difficult, practically impossible to separate the Internet resource from the media. Any Internet resource, providing information to the reader, entertaining him and stimulating him to organized social activities, causes one effect or another (Kislaya, 2012). Differences in the effects produced can be efficient, scale and of social significance.

The development of the Internet, taking place based on the synthesis of traditional Mass Media and the technical capabilities of the Internet, occupying a leading position in the process of providing information to the modern audience, in the formation of information society and an increase in civic engagement. It should be noted that the emergence and development of the Internet in Kyrgyzstan is spontaneous and does not have sufficient theoretical understanding and legal support. These factors determine the need to study the development trend of the Internet in the political, legal and economic conditions of Kyrgyzstan. The penetration of the Internet into the media has created a completely new system, which is characterizing by changes caused by the technical capabilities of the Internet. The massive spread of Internet has given rise to new forms of mass communication, which are characterized by deep interactivity, 
openness, lack of space and time constraints.

First, the Internet has its own social place, which differs from the "old" auditorium in a number of parameters.

Secondly, in Internet the new opportunities have appeared speedily and efficiently in updating their information, with a more flexible approach to a fixed frequency.

Thirdly, the Internet has a special distribution area, where information is distributed through new information and communication channels, which are global in nature, that is, global in the breadth of audience coverage and at the same time local in terms of accessibility to small social groups dispersed by interests and territory.

Fourthly, the areas of informational attention distinguished by both universalism and ultimate specialization, serving the interests of certain audience parts. Fifth, the Internet is expanding its content opportunities to perform functions such as information and entertainment.

An attempt to create a convergent mass media in Kyrgyzstan is the publication "Chalkan.kg". Chalkan.kg produces its own multimedia journalistic products and provides a full range of media, intellectual, copy-rating services. In fact, "Chalkan.kg" is a newspaper, website, Internet TV, production studio and conference service, that providing a platform for an information presentation, as news agencies do. Since in the Kyrgyz media system the concept of "convergent mass media" is still new and does not have a development strategy, today "Chalkan.kg" is an indicator of the most successful Internet project and a pioneer of startups in Internet.

Another innovative phenomenon in the field of mass media in modern Kyrgyzstan is web radio. As the Internet spreads in society, the web versions of radio stations are beginning to compete with traditional radio. The advantages of radio broadcasting for the Internet are global networks making it possible to reach the radio signals. This makes it possible to develop the Internet not only for independent radio but also for radio, which is created as an application.

For example, the Kyrgyz-Turkish University "Manas", along with its monthly magazine, created online radio "Manas Radio", which is contrary to expectations and has become popular among young people. Today here are top 10 popular radios in the country. This allows to listen to live radio, contains sound archives, interactive tools, news and advertising. In addition to opportunities for the mass spread of information, Internet opens up great opportunities for collective communication, for prompt discussion of a wide range of topics and urgent problems. Division of news into thematic groups led to the creation of interactive electronic conferences (discussion groups), accessible to the general user and allowing them to maintain thematic correspondence between participants.

The Internet compares favorably with traditional media in terms of economic aspects. It does not require the cost of media production, layout, and staff may not be as large as in conventional print media, instant access to all information, 
in-depth reading of hypertext attracts the reader, and most importantly, the audience chooses the Internet. Research by the State Communications Agency showed that in 2014, the total number of Internet users in Kyrgyzstan was 3 million 815 thousand people. Of these, 2 million 141, 7 thousand people are permanent users with free access to the Internet (Sulaimanova, 2019). For a developing country with 6.5 million inhabitants, this is considered a positive indicator. These users are the potential audience of the Internet. About $70 \%$ of the registered media have their own Internet versions, and monthly or quarterly publications or publish their materials in special text formats for use on the Internet, that is, one way or another, most media have their representations in the World Communication Network. The analysis of the logic of the construction of the rubric showed that several groups of the rubric of semantic interests can be distinguished:

1) Thematic interests, include such headings as "Politics", "Economics", "Events", "Society". These classical headings contain materials of national interest in these areas;

2) Local interests include the content study of Kyrgyz websites that have shown localization of interests observed in the Kyrgyz Internet due to the development of national color in the context of the media.

AKI press also has a feuilleton section called "Tales of Heavenly Beshbarmak", where the country's politicians act under fabulous names. The content of these headings is of interest only to the reader who permanently resides in the country and is aware of the latest political events.

\section{Special Events on the Internet}

There is a tendency to create thematic event headings for a short period. They, as a rule, are devoted to a separate significant event, which is relevant not only within the framework of national interests but also of international interest. Site "RIA Novosti" has such special event headings as "Arab coup", "War of 1812" and "Titanic", which presents thematic articles. After analyzing the information field of these information sites, its materials can be divided into 5 groups:

1) all copyrighted exclusive materials;

2) materials that are available through internal and external links;

3) user-generated content (comments, photos and videos);

4) multimedia materials;

5) content materials is an ad unit.

In addition to the popular genre of information note, rewriting and copywriting are common on the Internet. The practice of copywriting is permissible if an agreement on information exchange concluded between the editions and the links to the author observed. Rewriting is the most popular type of journalistic text on the Internet. For example, the editorial office of the AKI press Internet edition practices rewriting in the headings of international news.

The absence of a correspondent network in these countries and the period do 
not allow creating an exclusive text, therefore, based on the materials of the news agencies of these countries, the journalist creates an original text that meets all the requirements of the Internet: it has semantic content, does not violate copyright rights and concepts of this media.

Currently, there are 1730 websites in Kyrgyzstan, of which only 75 sites have Internet status. An online survey of Internet users, conducted in 2010 as part of a social research program "Priorities and interests of the Internet audience in Kyrgyzstan", revealed the following list of the most popular local resources: 1) Diesel forum—diesel.elcat.kg; 2) Namba—namba.kg; 3) Bit-torrent.kg-torrent.kg; 4) AKIpress-akipress.org; 5) Beelive-blive.kg.

Our research revealed that the annual Internet audience in 2014 grew by $11 \%$ and reached 3.815.000 unique users. This indicator most accurately reflects the number of real consumers and is the most important indicator when assessing the market position of sites. On average, users visited the site 2 times a day and spent 8 - 10 minutes for each visit. The Internet audience represented by young people aged 20 to 27 years - 50\% and from 27 to 40 years old are $30 \%$. Insignificant parts of Internet users are users aged 40 to 50 years are $20 \%$. Older people do not have the technical skills to use the Internet. Therefore, among the users, there are practically no people from 70 to 80 years old. Their information needs are fully satisfied by traditional media, whose principles and functions correspond to their range of interests.

\section{Gender Issues}

In terms of gender, the Internet audience in Kyrgyzstan remains as $60 \%$ are men among users, $40 \%$ are women. For news websites, this ratio is even higher: $65 \%$ are men, $35 \%$ are women. The share of women is usually higher for communication resources: social networks, chats, dating and culture. The economically active share age from 25 to 40 years old and it is $45 \%$ of the total audience interested in Internet news in Kyrgyzstan. The number of users aged from 19 to 24 is $25 \%$ and users aged from 41 to 50 years old are $15 \%$. Studies show that majority of Kyrgyz Internet users are socially active citizens, mostly males aged from 25 to 45 years old. These are university students, employees of government and commercial structures. The imbalance and concentration of Internet users in the capital is $77 \%$ of the total user's number. This is due to the passive use of access in the regions due to the low incomes of the population and the high cost of infrastructure development. This is one of the reasons for information inequality in countries and regions.

\section{Conclusion}

Traditional media do not satisfy information needs and therefore people prefer the Internet, which makes it possible to follow events online, and monitoring information sites allows them to obtain objective information. Internet site interactivity in forum sites allows users to have high self-organization and show civ- 
ic activity. Internet users have a larger amount of information. In addition to the Kyrgyz and Russian languages, they speak English at the level of simple conveying. These people have democratic views and are critical in political and economic situations happening in the country. Resource as the media undergoes registration in special issues regulating their activity, and legally defined as a media, endowed with rights and obligations, provided by law. The Internet compares favorably with traditional media in terms of economic aspects. Web radio is considered another innovative phenomenon in the field of mass media in modern Kyrgyzstan.

\section{Conflicts of Interest}

The authors declare no conflicts of interest regarding the publication of this paper.

\section{References}

Ahmed, S., \& Cho, J. (2019). The Roles of Different News Media Use and Press Freedom in Education Generated Participation Inequality: An Eight Country Comparative Analysis, Journal of Broadcasting \& Electronic Media, 63, 566-586. https://doi.org/10.1080/08838151.2019.1653100

Alvarez-Mon, M. A., Del Barco, A. A., Lahera, G., Quintero, J., Ferre, F., Pereira-Sanchez, V., Ortuño, F., \& Alvarez-Mon, M. (2018). Increasing Interest of Mass Communication Media and the General Public in the Distribution of Tweets about Mental Disorders: Observational Study. Journal of medical Internet Research, 20, e205. https://doi.org/10.2196/jmir.9582

Charron, N., \& Annoni, P. (2021). What is the Influence of News Media on People's Perception of Corruption? Parametric and Non-Parametric Approaches. Social Indicators Research, 153, 1139-1165. https://doi.org/10.1007/s11205-020-02527-0

CIS Legislation (2021). Law of the Kyrgyz Republic. https://cis-legislation.com/document.fwx?rgn=121

Fedorova, I. V. (2009). Mass Communication as a Communication Process. Bulletin of the Peoples' Friendship University of Russia, 3, 83-88.

Fomicheva, I. D. (2012). Media among the Means of Social Communication. Moscow University Bulletin, 1, 60-72.

Kislaya, L. N. (2012). Internet Resources as a Factor in Attracting a Youth Audience (On the Example of Regional Newspapers of the Novosibirsk Region). Journalistic Yearbook, 1, 45-47.

Lukina, M. M., \& Fomicheva, I. D. (2005). Mass Media in Internet Space. Moscow: Moscow State University Journalistic Faculty, $87 \mathrm{p}$.

Lund, B. D., \& Wang, T. (2021). Information Dissemination and Interactions in Higher Education Social Media Posts. Journal of Promotion Management, 27, 547-561. https://doi.org/10.1080/10496491.2020.1851848

Materials of the International Organization (1999) Mass Media of Central Asia: Present and Future. Bishkek.

Panusheva, M. M. (2010). Blogsphere: Traditional and Non-Traditional Mass Media Sources. Moscow State University Bulletin, 4, 106-122.

Pulido, C. M., Redondo-Sama, G., Sordé-Martí, T., \& Flecha, R. (2018). Social Impact in 
Social Media: A New Method to Evaluate the Social Impact of Research. PLOS ONE, 13, e0203117. https://doi.org/10.1371/journal.pone.0203117

Saima \& Khan, A. M. (2021). Effect of Social Media Influencer Marketing on Consumers' Purchase Intention and the Mediating Role of Credibility. Journal of Promotion Management, 27, 503-523. https://doi.org/10.1080/10496491.2020.1851847

Semakula, D., Nsangi, A., Oxman, M., Rosenbaum, S. E., Oxman, A. D., AustvollDahlgren, A., Glenton, C., Lewin, C., Kaseje, M., Morelli, A., Fretheim, M., \& Sewankambo, K. (2019). Development of Mass Media Resources to Improve the Ability of Parents of Primary School Children in Uganda to Assess the Trustworthiness of Claims about the Effects of Treatments: A Human-Centred Design Approach. Pilot Feasibility Stud, 5, Article No. 155. https://doi.org/10.1186/s40814-019-0540-4

Shagdarova B. B., \& Vilmova, K. K. (2018). Online Journalism and New Media. Bulletin of the Buryat State University. Language, Literature, Culture, 4, 64-68.

Sulaimanova, M. (2019). The Number of Internet Users in Kyrgyzstan is Growing Every Year.

http://kabar.kg/news/kolichestvo-internet-pol-zovatelei-kyrgyzstana-ezhegodno-rastetdogoev/

Tikhomirova, E. I. (2017). Communication Theory and New Media. Problematic field of Media Education, 3, 218-221.

Tsakhaev, R. K. M., \& Musieva, P. A. (2008). Non-Traditional Media as a Promising Means of Marketing Communications. Economic Structuring Issues, 1, 91-92.

USAID (2021). Media Support Initiative. https://www.usaid.gov/kyrgyz-republic/fact-sheets/media-support-initiative. 